\title{
Awareness and Use of Community Services among Primary Care Physicians
}

\section{Connaissance et utilisation des services communautaires par les médecins de première ligne}

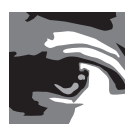

TARA KIRAN, MD, MSC, CCFP, FCFP

Family Physician

St. Michael's Hospital

Associate Professor, Department of Family and Community Medicine

Faculty of Medicine and the Institute of Health Policy, Management and Evaluation

University of Toronto

Scientist, MAP Centre for Urban Health Solutions

Li Ka Shing Knowledge Institute, St. Michael's Hospital

Toronto, ON

JESSICA J. RODRIGUES, MSC

Research Coordinator, MAP Centre for Urban Health Solutions

Li Ka Shing Knowledge Institute, St. Michael's Hospital

Toronto, ON

TATIANA ARATANGY, PHD

Manager, Survey Research Unit, MAP Centre for Urban Health Solutions

Li Ka Shing Knowledge Institute, St. Michael's Hospital

Toronto, ON

KIMBERLY DEVOTTA, MA

Research Coordinator, MAP Centre for Urban Health Solutions

Li Ka Shing Knowledge Institute, St. Michael's Hospital

Toronto, ON

NATHALIE SAVA, MHSC, MSW, RSW

Senior Planner, Health Analytics and Innovation, Toronto Central Local Health Integration Network

Toronto, ON

PATRICIA O'CAMPO, PHD

Scientist, MAP Centre for Urban Health Solutions

Li Ka Shing Knowledge Institute, St. Michael's Hospital

Professor, Dalla Lana School of Public Health

University of Toronto

Toronto, ON 


\begin{abstract}
Primary care physicians play an important role in care coordination, including initiating referrals to community resources. Yet, it is unclear how awareness and use of community resources vary between physicians practising with and without an extended healthcare team. We conducted a cross-sectional survey of primary care physicians practising in Toronto, Canada, to compare awareness and use of community services between physicians practising in team- and non-team-based practice models. Team-based models included Community Health Centres and Family Health Teams - settings in which the government provides funding for the practice to hire non-physician health professionals, such as social workers, pharmacists, nurse practitioners, registered nurses and others. The survey was mailed to physicians, and reminders were done by phone, fax and e-mail. We used logistic regression to compare awareness between physicians in team-based $(N=89)$ and non-team-based $(N=138)$ models after controlling for confounders. We found that fewer than half of the physicians were aware of five of eight centralized intake services (e.g., ConnexOntario, Telehomecare). For most services, team-based physicians had at least twice the odds of being aware of the service compared to non-team-based physicians. Our findings suggest that patients in team-based practices may be doubly advantaged, with access to non-physician health professionals within the practice as well as to physicians who are more aware of community resources.
\end{abstract}

\title{
Résumé
}

Les médecins de première ligne jouent un rôle important dans la coordination des soins, notamment en aiguillant des patients vers les ressources communautaires. Toutefois, on ne sait à quel point le degré de connaissance et l'utilisation des ressources communautaires varient entre, d'une part, les médecins qui exercent leur pratique au sein d'une équipe de soins multidisciplinaire et, d'autre part, ceux qui exercent leur pratique en dehors de tels équipes. Nous avons mené une enquête intersectorielle auprès des médecins de première ligne qui œuvrent à Toronto, en Ontario, afin de comparer le degré de connaissance et l'utilisation des services communautaires entre les deux modèles de pratique. Les modèles d'équipes comprennent les centres de santé communautaire et les équipes Santé familiale - des organismes dont le gouvernement finance le recrutement de professionnels de la santé non médecins tels que les travailleurs sociaux, les pharmaciens, les infirmières praticiennes, les infirmières autorisée et autres. L'enquête a été envoyée par la poste aux médecins, puis a fait l'objet de rappels par téléphone, par télécopie et par courriel. Nous avons employé la régression logistique pour comparer le degré de connaissance des ressources communautaires entre les médecins qui travaillent au sein d'équipes $(N=89)$ et ceux qui travaillent en dehors de ces équipes $(N=138)$, après contrôle des facteurs de confusion. Nous avons observé que moins de la moitié des médecins avaient connaissance de cinq des huit points d'accès centralisés (p. ex., ConnexOntario ou Telehomecare). Pour la plupart des services, les médecins qui pratiquent au sein d'équipes sont au moins deux fois plus susceptibles d'avoir connaissance d'un 
service, comparativement aux médecins qui n'œuvrent pas au sein d'une équipe. Nos résultats suggèrent que les patients qui consultent dans les pratiques où se trouvent des équipes bénéficient d'un double avantage, d'une part grâce à l'accès aux professionnels de la santé non médecins, et d'autre part grâce aux médecins qui sont plus au fait des ressources communautaires disponibles.

\section{Introduction}

It is well-accepted that systems with strong primary care have lower costs and better outcomes (Starfield et al. 2005). Starfield (1992) described four core elements of primary care, commonly referred to as the four Cs: provision of first Contact care, Continuity of care over time, Comprehensiveness or concern for the whole person rather than one organ system and Coordination with other parts of the healthcare system. Primary care's role in care coordination is particularly relevant, given the global rise in chronic disease prevalence and multi-morbidity (Starfield et al. 2003). Care coordination involves judicious referral to specialists for support in managing chronic conditions and also connecting with community and social services that enable patients and families to effectively self-manage their conditions. Effective coordination with social and community services has implications for health equity, given the intersection between multi-morbidity and social deprivation (Barnett et al. 2012).

In Canada, coordination between traditional healthcare services and community services can be challenging, given the sectors are largely funded and operated separately. There are also large gaps in public coverage for the latter (Martin et al. 2018). Every year, approximately one in five Canadians experience a mental health condition (Mental Health Commission of Canada 2013), yet timely access to community-based mental health services in Canada is a particular challenge (Brien et al. 2015; Kurdyak et al. 2017; MHASEF Research Team 2017). More than two thirds of the people with a mental health condition are seen by a primary care physician, either alone or by other additional health professionals (Jaakkimainen et al. 2006), underscoring the important role primary care physicians play in coordinating care for this group.

\section{Primary care in Ontario and access to the extended bealthcare team}

Ontario is Canada's largest province. Primary care physician services are fully insured by the provincial health insurance plan and free at the point of care for all permanent residents. Public coverage for community supports varies, with some services being fully covered (e.g., diabetes education), some not covered (e.g., Meals on Wheels) and some covered through both public and private options (e.g., weight management). Over the past two decades, Ontario has invested considerable resources in reforming primary care. Ontario has introduced new types of practice models that incorporate aspects of the Patient Medical Home, including formal patient enrolment, blended capitation payment, coordinated after-hours' access and, in some cases, funding for non-physician health professionals, such as registered nurses, nurse practitioners, pharmacists or social workers (Hutchison et al. 2011). 
There are two predominant team-based primary care models, Family Health Teams (FHTs) and Community Health Centres (CHCs). In these models, the practice receives dedicated government funding to hire non-physician team members. Members of the extended healthcare team work collaboratively with primary care physicians in the practice and provide a range of services at no out-of-pocket cost to patients (i.e., extended health team services in the practice are covered under provincial health insurance). Examples include nurse practitioners counselling for smoking cessation, pharmacists conducting medication reviews, dietitians and nurses supporting diabetes education and social workers providing cognitive behavioural therapy for depression or providing case management for supporting a housing search. There is heterogeneity between team-based practices in the mix of health professionals and the programs they offer. Patients who are not part of a team-based model generally do not have free access to non-physician health professionals within the provincial health insurance plan. For example, patients not in a team-based model would need to pay privately, through third-party insurance or out of pocket, to see a social worker for counselling or for case management support.

In other jurisdictions, team-based models have been shown to support more effective chronic disease prevention and management (Bodenheimer et al. 2002) and lower healthcare use and costs (Reiss-Brennan et al. 2016). However, only one quarter of Ontarians are attached to a physician practising in a team-based model (Peckham et al. 2018), and access varies 10-fold across regions in the province (Glazier et al. 2018; Green et al. 2017) and is variable even within a single health region.

\section{Community services in the region}

One strategy to address inequities in access to team-based care in Ontario has been to try and enhance community services, which would be available to all patients, regardless of their physician's practice model. At the time of study, the regional health authority directly funded many community services, including diabetes education programs, or programs to support healthy eating, employment support or smoking cessation. The health authority also developed centralized intake services - a central point of contact supporting navigation of community services for a population or condition, such as one number to call to access addiction support services. Some community and centralized intake services require a physician referral, whereas others do not. At the time of study, most centralized intake services had been operating for about five years, whereas most community services were long-standing, having been established for two or more decades. However, it was unclear how much these community services were being used by physicians and their patients and whether these services effectively mitigate inequities in access to team supports embedded in primary care practices. 


\section{Study objective}

Research from three decades ago found low awareness of community services among family physicians overall (Craven et al. 1990). However, there has been little work to quantify the issue in the modern era, where there is easy access to information via the internet. Recent qualitative research suggested that it was still challenging for family physicians to keep abreast of available community services, for example, because of out-of-date resources or that non-physician team members helped facilitate linkages with community resources (Ploeg et al. 2017). Accordingly, our study aimed to better understand family physicians' current awareness and use of community resources and how these were influenced by access to nonphysician team members.

We conducted a cross-sectional survey to understand awareness and use of community services among primary care physicians practising in an urban region of Ontario, including services for people with mental health and addictions, for seniors and for those requiring chronic disease prevention and management. We sought to understand whether awareness and use of community services were different for physicians practising in a team-based versus a non-team-based model. We defined FHTs and CHCs as the team-based models of interest because, in these models, the government provides the practice with dedicated funds to hire non-physician health professionals to work alongside primary care physicians.

\section{Method}

\section{Setting and context}

The study was conducted in the Toronto Central Local Health Integration Network (TC LHIN) health region, which encompasses downtown Toronto. Toronto is Canada's largest city, with a population of approximately 2.7 million residents in 2016. Approximately $17 \%$ of the patients in Toronto receive care from a physician practising in a team-based model, $15 \%$ in an FHT and 2\% in a CHC (Glazier et al. 2018; P. Gozdyra, personal communication, August 21, 2019). CHCs were introduced in the 1970s; these have traditionally been located in areas with greater social deprivation, often have formal catchment areas or specific populations that they serve and are mostly governed by community-led boards. FHTs were introduced in 2005; few have catchment or specific population inclusion criteria, and many are governed by a physician-led board. Physicians in CHCs are employees and are paid on salary, whereas physicians in FHTs are self-employed and are paid through blended capitation.

Non-team-based models include ones with formal patient enrolment where physicians are either paid largely through capitation with some shadow billing (Family Health Network, Family Health Organization) or largely via fee-for-service with some capitation payments (Family Health Group, Comprehensive Care Model). Some physicians continue to practice outside a patient enrolment model and are paid solely through fee-for-service. Physicians 
practising in these models generally do not receive funding to hire non-physician health professionals as a part of their team, although they may use their own earnings to pay, for example, for a nurse or nurse practitioner to work in their team.

\section{Study design and population}

We conducted a cross-sectional survey of primary care physicians practising in the TC LHIN health region. Data were collected over six months, between October 2015 and March 2016. The study was initiated by the TC LHIN to better understand the behaviours, barriers and facilitators for community referrals among primary care physicians who practiced in the region. A "community referral" was defined in the study as the scheduling or arranging for a patient to attend a (non-physician) service in the community, either directly or via a centralized intake service. It did not include referrals to medical specialists, diagnostics, lab work or long-term care.

Survey participants were selected using stratified random sampling based on geographic subregions and neighbourhoods. The TC LHIN received a list from the Ontario Ministry of Health and Long-Term Care of physicians practising primary care in the health region, including their practice address. Physicians were included in the sample if they were practising in one of the TC LHIN neighbourhoods at the start of the study. Physicians were excluded if they were known to have a focused practice other than geriatrics (e.g., psychotherapy, sports medicine, etc.). The study received approval by the Research Ethics Board of St. Michael's Hospital in Toronto, Ontario.

\section{Survey design}

A literature search was conducted to inform the initial content of the questions. An academic librarian searched CINAHL, Medline and PubMed around the topic of primary healthcare providers and their referrals of patients to community services. Consultations were then conducted with primary care providers and other physicians based in Toronto, to compile a more comprehensive list of community services for the survey. Study staff met with these physicians in person to get their feedback on what was missing or duplicated in the list. Lead primary care advisors and other staff at the TC LHIN also reviewed the survey for content, and their feedback was given to the study team. The survey asked physicians about their community referral practices and related barriers and facilitators and asked them to provide demographic information, including their sex, age, practice size, practice location and practice model. The survey was then piloted with a small group of physicians for formatting and content before the survey was widely distributed for the project. Four physicians completed the survey on paper in the first round, and then two completed the web version in the second round of piloting. In both rounds, physicians were asked to complete the survey on their own and were then asked a series of questions by the study staff (e.g., "How did you come to your response and pick an option?", "How do you recall who makes the referrals in your practice?" "How do you recall overcoming barriers and making the referrals yourself?"). The survey 
questions are listed in Appendix 1 (available online at longwoods.com/content/26290). The final survey included 17 questions over four pages and was made available via mail, fax and web.

\section{Participant recruitment}

Approximately 1,700 physicians met the inclusion criteria. Over the course of two waves, 1,000 of these physicians were invited to participate in the cross-sectional survey (Figure 1). We originally aimed for a 50\% recruitment rate. All sampled physicians were initially invited through mailed study materials in October 2015 ( $N=500)$ and January 2016 $(N=500)$. All physicians were initially mailed an invitation and up to two follow-up reminders. All mailouts included a paper version of the survey with a postage paid envelope to return it to the study team as well as a web link if they preferred to complete the survey online. A recruitment database was set up to track completed surveys and returned letters, so physicians who completed the survey or were no longer eligible (e.g., inactive practice, change of practice location, etc.) did not continue to receive follow-ups. Phone, e-mail, fax and on-site follow-ups were conducted in between each mailout, the outcomes of which were all recorded in the recruitment database. If the study team had access to a fax number (publicly listed or provided during a phone follow-up), the team faxed a copy to the office. The majority of respondents completed the paper survey following the initial mailout. The web survey was the second most successful strategy, followed by fax. Some practices were selected to receive on-site visits by study staff in between the second and third mailout. Sites geographically closest to the study team with some of the highest numbers of outstanding surveys were chosen for on-site visits. Although this strategy was not successful in getting physicians to complete it on the spot, it did allow study staff to leave an additional copy of the mailed package with the clerical staff. At minimum, all physicians received at least one phone followup in addition to the mailouts, unless they completed the survey before the end attempt, refused to complete or were found ineligible.

We used the College of Physicians and Surgeons of Ontario public directory to update respondents' contact information and primary practice location throughout the study, ensuring currency of information and participant eligibility. Throughout the course of data collection, physicians who completed the survey were offered the opportunity to be entered into a draw for a tablet. Draws took place at three different time points in the data collection period, so the earlier a physician completed their survey, the more draws they were entered in. In the last few months of the study, additional tablets were added for administration staff at the winning physician's offices to further encourage timely completion, as physicians who completed the survey could have the chance to win a tablet for themselves and a clerical staff member. No honorarium was provided. After the invitations were mailed out, a total of 105 physicians were found to be ineligible (no longer practising primary care, relocated to outside of TC LHIN geography, on leave), whereas 278 physicians had no confirmed contact information, or there was no way to confirm we reached them (e.g., unable to leave a message 
FIGURE 1. Flowchart of physicians invited to participate in the survey $(N=1,000)$

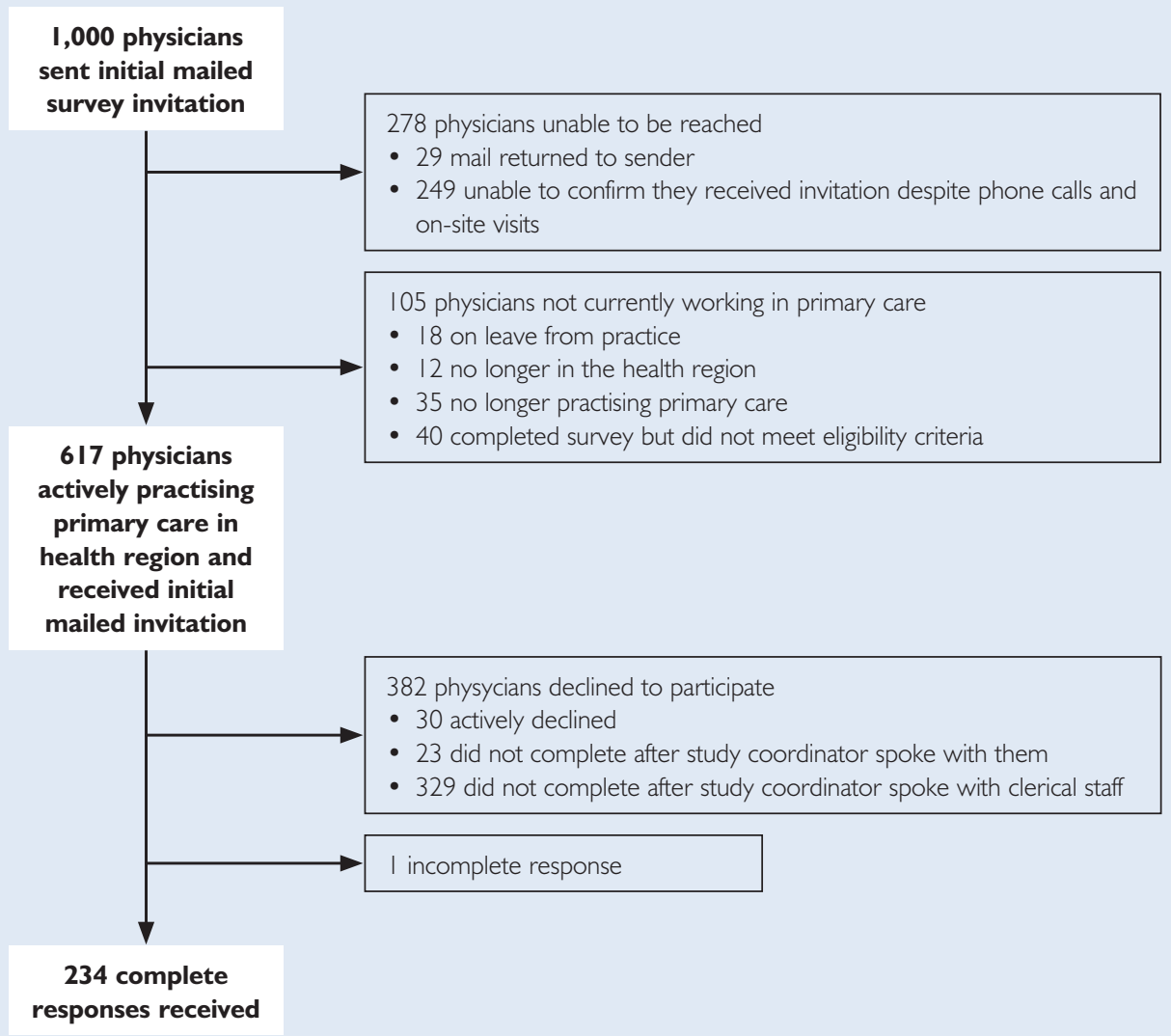

about the study with anyone at the practice). Recruitment rates were calculated excluding these 383 physicians from the sample.

\section{Analysis of responses}

In the analysis, we stratified physicians by whether they practiced in a team-based model or not at the time of sampling. Team-based models included physicians practising in CHCs or FHTs. Non-team-based models included physicians practising in Family Health Organizations, in Family Health Groups and in the Comprehensive Care Model or those who were practising traditional fee-for-service. We included all data from surveys with partial responses as long as physicians identified their practice model and the number of patients in their practice. We used $\chi^{2}$ tests to compare physician demographic characteristics (age, sex and years of practice in Toronto) between the team-based and non-team-based practice models. We examined respondents' practice characteristics (panel size, patient population and community referrals) using $t$ tests. 
We conducted binomial logistic regression analyses to determine the associations between a physician's practice models and their awareness and use of community services. We assessed awareness and use of 24 services designed to support (i) mental health and addictions, (ii) chronic disease and management and (iii) seniors within TC LHIN boundaries. Eight of these services were categorized as centralized intake services. For all models, we included the practice model, sex of the respondent and years practising as covariates. For models relating to (i) mental health and addictions and (ii) chronic disease prevention and management, we also included the physician's estimation of the prevalence in their practice (i.e., percentage of patients in their main Toronto practice with severe mental illness and/or addiction problems and percentage medically complex, respectively). We decided a priori not to make adjustments for multiple comparisons, given that our study was hypothesis-generating (not hypothesis-testing), and we worried that adjustments for multiple comparisons could inflate Type II error. Graphpad Prism 7 was used to plot the adjusted odds ratios. All other analyses were conducted using IBM SPSS Statistics, Version 24.

\section{Results}

In total, 234 of 617 eligible primary care physicians completed the survey $(69.7 \%$ by paper, $20.5 \%$ by web and $9.8 \%$ by fax). Seven respondents were excluded from the analysis because they did not specify either a practice model or the number of patients in their practice. A total of 227 physicians were included in our analysis.

In total, 89 (39\%) respondents identified practising in a team-based model (68 in an FHT and 21 in a CHC). The two most common non-team-based models were the Family Health Group $(N=46)$ and the Family Health Organization $(N=61)$. Physicians in team-based models were more likely to be female, to be less than 50 years of age and to report practising in Toronto for fewer than 15 years (Table 1 ).

The mean roster size of team-based physicians was almost half that of the non-teambased physicians (Table 2). Team-based physicians reported caring for a higher proportion of patients who were uninsured, medically complex, recent immigrants, dealing with poverty or had severe mental illness or addictions. Team-based physicians estimated that, on average, most community referrals were initiated by themselves (73\%), with the next most common referents being social workers (18\%). Non-team-based physicians estimated that a higher proportion of community referrals were initiated by themselves (93\%) but also reported that other professionals initiated some of the referrals.

Figure 2 summarizes the awareness and use of community services among physicians in team-based versus non-team-based practice models. Fewer than half of physicians were aware of four of the five centralized intake services for people with mental health and addictions (Figure 2a); awareness was not significantly different between physicians in team-based and 
TABLE 1. Characteristics of survey respondents $(N=227)$ by non-team-based and team-based practice model*

\begin{tabular}{|c|c|c|c|c|}
\hline \multicolumn{2}{|c|}{ Physician provider demographics } & $\begin{array}{l}\text { Non-team-based } \\
\qquad(\boldsymbol{N}=138)\end{array}$ & $\begin{array}{l}\text { Team-based } \\
\qquad(N=89)\end{array}$ & $p$ \\
\hline \multirow{2}{*}{$\begin{array}{l}\text { Gender } \\
\text { (N, percentage column) }\end{array}$} & \multirow[t]{2}{*}{ Female } & 7I & 64 & \multirow[t]{2}{*}{0.002} \\
\hline & & 51.4 & 71.9 & \\
\hline \multirow{8}{*}{$\begin{array}{l}\text { Age range (years) } \\
(\mathrm{N}, \text { percentage column) }\end{array}$} & \multirow[t]{2}{*}{$<39$} & 31 & 39 & \multirow[t]{8}{*}{0.000} \\
\hline & & 22.5 & 43.8 & \\
\hline & \multirow[t]{2}{*}{$40-49$} & 23 & 23 & \\
\hline & & 16.7 & 25.8 & \\
\hline & \multirow[t]{2}{*}{$50-59$} & 27 & 13 & \\
\hline & & 19.6 & 14.6 & \\
\hline & \multirow[t]{2}{*}{$60+$} & 57 & 14 & \\
\hline & & 41.3 & 15.7 & \\
\hline \multirow{10}{*}{$\begin{array}{l}\text { Years practising in Toronto (years) } \\
\text { ( } \mathrm{N} \text {, percentage column) }\end{array}$} & \multirow[t]{2}{*}{$\leq 5$} & 24 & 29 & \multirow[t]{10}{*}{0.000} \\
\hline & & 17.4 & 32.6 & \\
\hline & \multirow[t]{2}{*}{$6-14$} & 24 & 28 & \\
\hline & & 17.4 & 31.5 & \\
\hline & \multirow[t]{2}{*}{ |5-29 } & 32 & 19 & \\
\hline & & 23.2 & 21.3 & \\
\hline & \multirow[t]{2}{*}{$30+$} & 53 & 11 & \\
\hline & & 38.4 & 12.4 & \\
\hline & \multirow[t]{2}{*}{ Missing } & 5 & 2 & \\
\hline & & 3.6 & 2.2 & \\
\hline \multirow{10}{*}{$\begin{array}{l}\text { Sub-LHIN region } \\
\text { (N, percentage column) }\end{array}$} & \multirow[t]{2}{*}{ East } & 23 & 14 & \multirow[t]{10}{*}{0.000} \\
\hline & & 16.7 & 15.7 & \\
\hline & \multirow[t]{2}{*}{ Mid-East } & 13 & 28 & \\
\hline & & 9.4 & 31.5 & \\
\hline & \multirow[t]{2}{*}{ Mid-West } & 58 & 30 & \\
\hline & & 42.0 & 33.7 & \\
\hline & \multirow[t]{2}{*}{ North } & 27 & 6 & \\
\hline & & 19.6 & 6.7 & \\
\hline & \multirow[t]{2}{*}{ West } & 17 & 11 & \\
\hline & & 12.3 & 12.4 & \\
\hline
\end{tabular}

*Non-team-based practice models include physicians in the Comprehensive Care Model, Family Health Groups, Family Health Organizations or fee-for-service model. Team-based models include physicians in FHTs or CHCs. 
TABLE 2. Practice characteristics of survey respondents $(N=227)$ by non-team-based and teambased practice model ${ }^{\dagger}$

\begin{tabular}{|c|c|c|c|c|}
\hline \multicolumn{2}{|c|}{ Practice demographic } & \multirow{2}{*}{$\begin{array}{l}\text { Non-team-based } \\
110 \\
1416.12 \pm 982.99\end{array}$} & \multirow{2}{*}{$\begin{array}{l}\text { Team-based } \\
77 \\
776.16 \pm 464.69\end{array}$} & \multirow{2}{*}{$\frac{p}{0.000}$} \\
\hline $\begin{array}{l}\text { Panel size } \\
(N, M \pm S D)\end{array}$ & $\begin{array}{l}\text { Average number of patients in } \\
\text { main Toronto practice }\end{array}$ & & & \\
\hline \multirow{6}{*}{$\begin{array}{l}\text { Percentage of patients } \\
\text { in main Toronto } \\
\text { practice who ... } \\
(N, M \pm S D)\end{array}$} & $\begin{array}{l}\text {... are uninsured (e.g., do not } \\
\text { have } \mathrm{OHIP} \text { ) }\end{array}$ & $\begin{array}{l}|3| \\
2.87 \pm 9.93\end{array}$ & $\begin{array}{l}85 \\
8.87 \pm 17.32\end{array}$ & 0.004 \\
\hline & $\begin{array}{l}\text {... are dealing with poverty and/or } \\
\text { housing instability }\end{array}$ & $\begin{array}{l}134 \\
10.82 \pm 14.19\end{array}$ & $\begin{array}{l}88 \\
30.51 \pm 28.26\end{array}$ & 0.000 \\
\hline & $\begin{array}{l}\text {... are medically complex (e.g., } \\
\text { multiple chronic health issues) }\end{array}$ & $\begin{array}{l}137 \\
27.16 \pm 22.95\end{array}$ & $\begin{array}{l}89 \\
38.02 \pm 24.31\end{array}$ & 0.001 \\
\hline & $\begin{array}{l}\text {... have severe mental illness and/ } \\
\text { or addiction problems }\end{array}$ & $\begin{array}{l}136 \\
11.47 \pm 11.67\end{array}$ & $\begin{array}{l}89 \\
20.02 \pm 17.01\end{array}$ & 0.000 \\
\hline & $\begin{array}{l}\text {... are composed of recent } \\
\text { immigrants (arrived in Canada } \\
\text { within five years or less) }\end{array}$ & $\begin{array}{l}134 \\
10.60 \pm 13.86\end{array}$ & $\begin{array}{l}88 \\
16.78 \pm 22.42\end{array}$ & 0.023 \\
\hline & ... have language barriers & $\begin{array}{l}135 \\
13.69 \pm 21.54\end{array}$ & $\begin{array}{l}88 \\
13.45 \pm 16.68\end{array}$ & 0.932 \\
\hline \multirow{4}{*}{$\begin{array}{l}\text { Percentage of } \\
\text { community service } \\
\text { referrals for your } \\
\text { patients that are } \\
\text { from ... } \\
(N, M \pm S D)\end{array}$} & ... yourself & $\begin{array}{l}76 \\
92.88 \pm 16.05\end{array}$ & $\begin{array}{l}123 \\
73.19 \pm 22.39\end{array}$ & 0.000 \\
\hline & ... nurse practitioner & $\begin{array}{l}42 \\
2.12 \pm 4.51\end{array}$ & $\begin{array}{l}56 \\
7.09 \pm 8.29\end{array}$ & 0.000 \\
\hline & ... social worker & $\begin{array}{l}51 \\
7.41 \pm 11.31\end{array}$ & $\begin{array}{l}68 \\
17.97 \pm 18.02\end{array}$ & 0.000 \\
\hline & ... other & $\begin{array}{l}40 \\
12.73 \pm 21.00\end{array}$ & $\begin{array}{l}35 \\
11.98 \pm 10.79\end{array}$ & 0.845 \\
\hline
\end{tabular}

${ }^{\dagger}$ Non-team-based practice models include physicians in the Comprehensive Care Model, Family Health Groups, Family Health Organizations or fee-for-service model. Team-based models include physicians in FHTs or CHCs.

non-team-based practice models, with one exception (withdrawal management services). The majority of physicians were aware of other community services for people with mental health and addictions (Figure 2b); for all of these services, team-based physicians had significantly higher awareness of and use of these services than non-team-based physicians.

\section{Figure 2.}

Proportion of primary care physicians who reported awareness of and use of community support services by non-team-based and team-based practice model.

For each subset of community services, physicians reported being not aware, aware and not used services, or aware and used services. $N=227$ for all services unless specified elsewhere. CS in parentheses refers to Centralized Intake Service. Non-team-based practice models include physicians in the Comprehensive Care Model, Family Health Groups, Family Health Organizations or fee-for-service model. Team-based models include those in FHTs or CHCs. 
FIGURE 2A. Centralized intake services for people with mental health and addictions

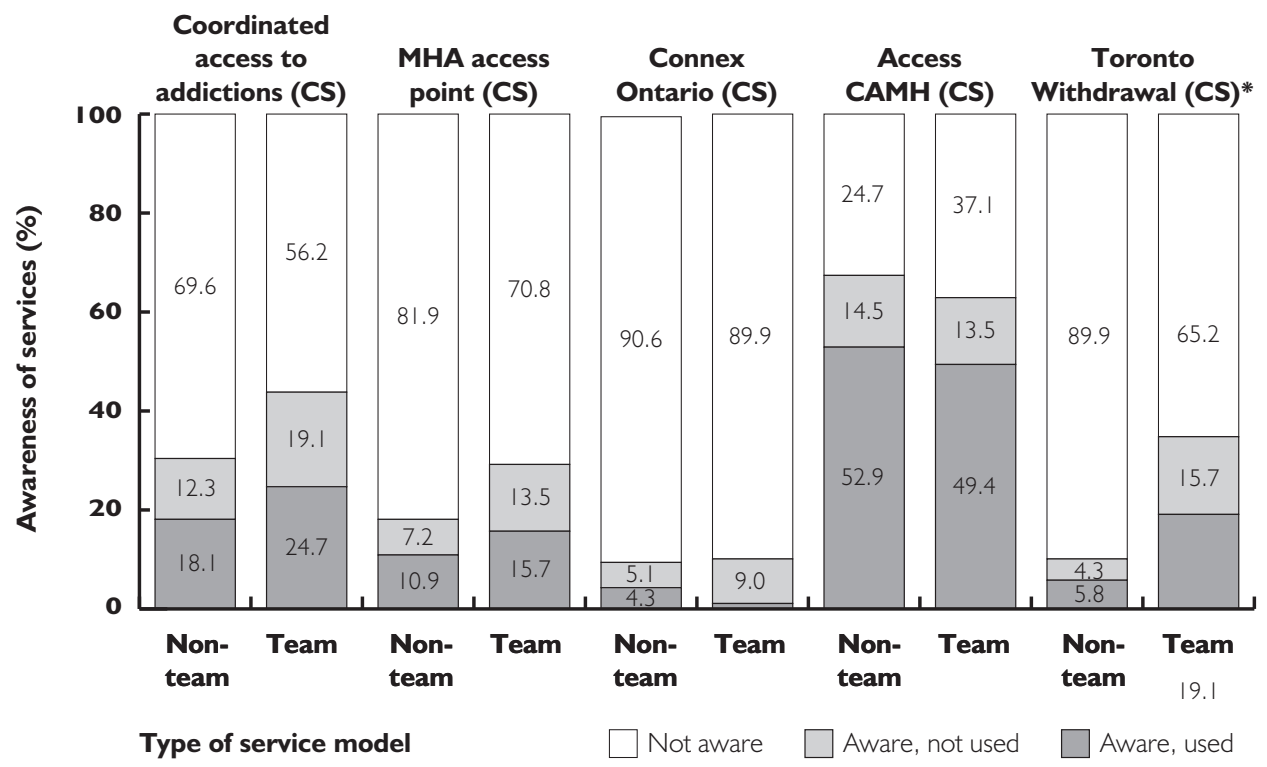

* $p<0.05$

FIGURE 2B. Other services for people with mental health and addictions

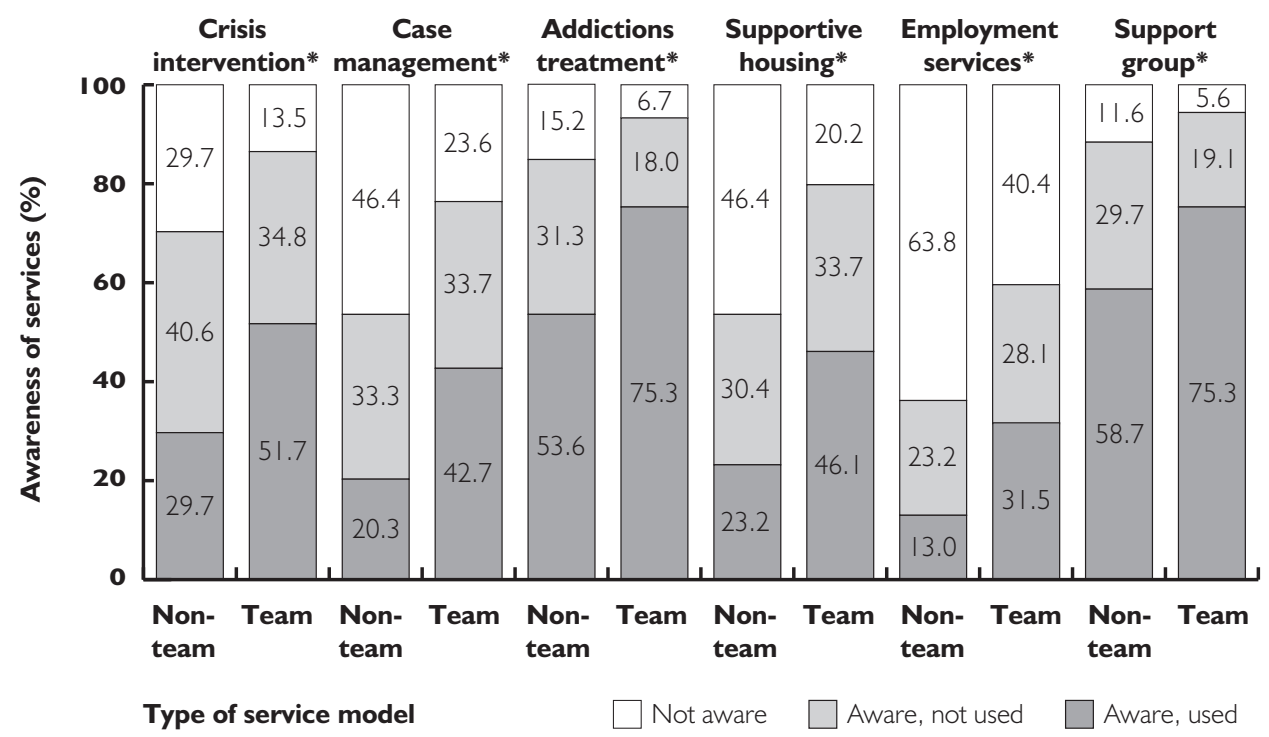


FIGURE 2C. Services to support chronic disease prevention and management

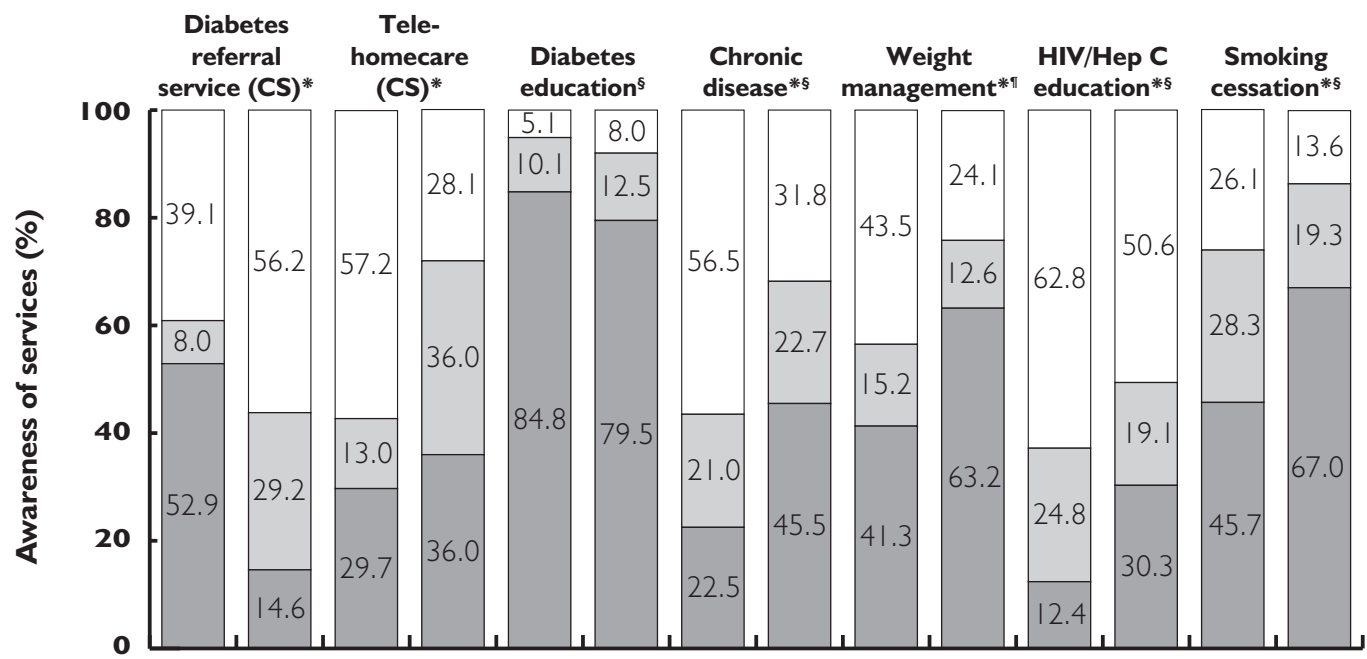

Non- Team Non- Team Non- Team Non- Team Non- Team Non- Team Non- Team team team team team team team team

Type of service model

$*_{p}<0.05 . \S N=226 ; \uparrow N=225$

FIGURE 2D. Services to support seniors

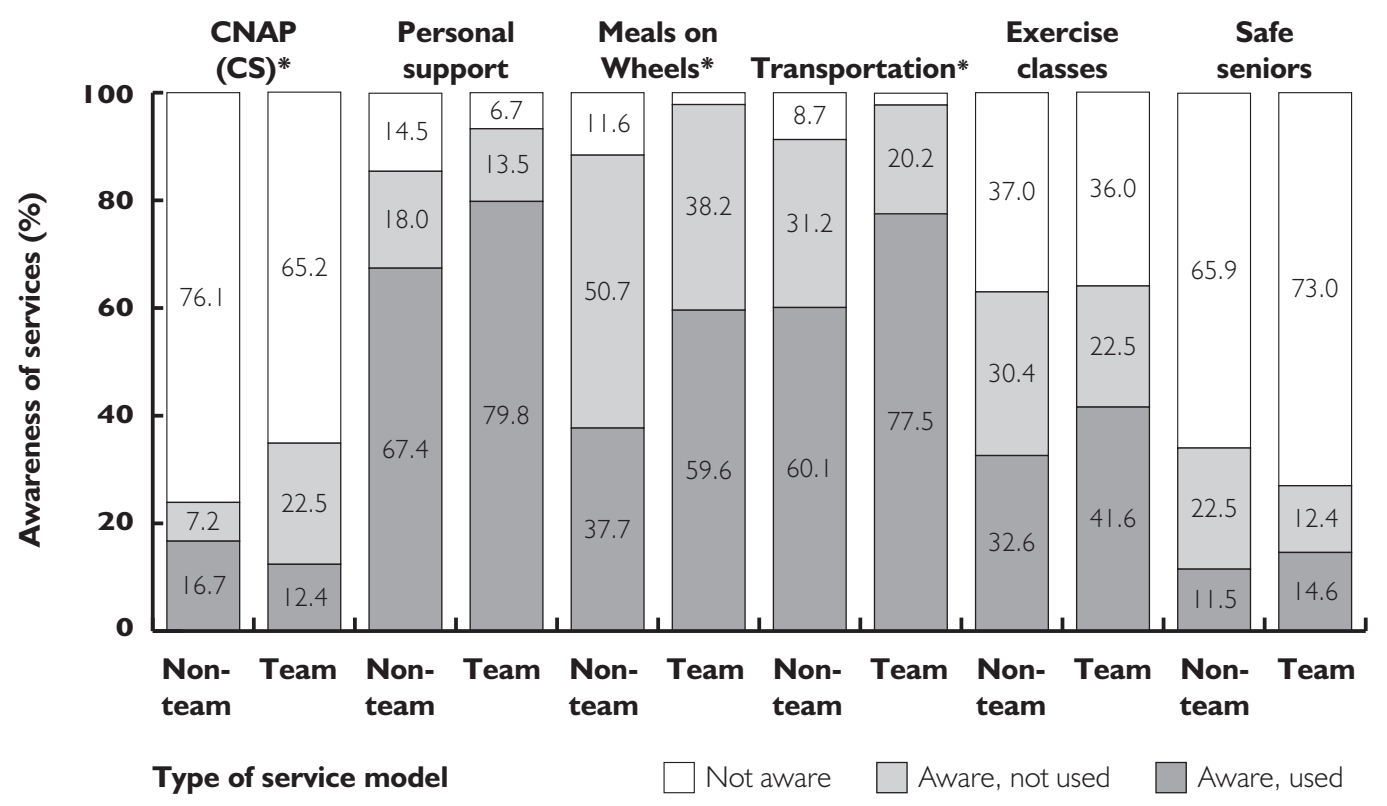


The majority of physicians were aware of chronic disease prevention and management services (Figure 2c); for most of these services, team-based physicians had significantly higher awareness of and use of the services than non-team-based physicians. There was relatively high awareness about some senior support services and low awareness about other services including the service coordinating centralized intake (Figure 2d); for half of the services, team-based physicians had significantly higher awareness of and use of the services than nonteam-based physicians, and for the other half there was no significant difference.

Figure 3 summarizes the odds that team-based physicians were aware of a community service compared to non-team-based physicians after adjustment for potential confounders. Overall, adjusted odds were similar to unadjusted odds. For most services, team-based physicians had at least twice the odds of being aware of the service compared to non-teambased physicians. There was only one service (centralized intake for diabetes services) where non-team-based physicians had significantly greater odds of awareness than teambased physicians (Figure 3c).

\section{Figure 3.}

Odds ratio (with 95\% confidence intervals) comparing awareness of community services among physicians in team-based versus non-team-based practice models after adjustment for physician demographics (practice model, sex and years of practice) and relevant practice demographics (severe mental illness and/or addiction problems, medically complex patients)

$N=227$ for all services unless specified elsewhere. CS in parentheses refers to Centralized Intake Service. Team-based models include those in FHTs or CHCs. Nonteam-based practice models include physicians in the Comprehensive Care Model, Family Health Groups, Family Health Organizations or fee-for-service model.

FIGURE 3A. Centralized intake services for people with mental health and addictions

\section{Community service}

Coordinated access to addictions services (CS)

$\mathrm{MHA}$ access point (CS)

ConnexOntario (CS)

AccessCAMH (CS)

Toronto Withdrawal (CS)

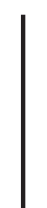

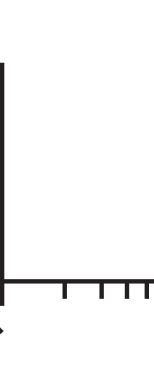

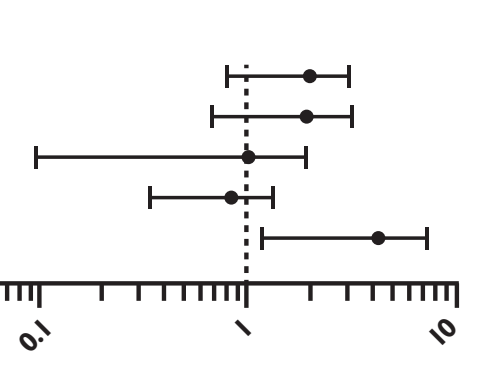

aOR (95\%Cl)

I.737 (0.931-3.24)

$1.665(0.825-3.358)$

$0.737(0.266-2.047)$

$0.729(0.391-1.358)$

$3.523(1.608-7.719)^{* * *}$

Adjusted Odds Ratio 
FIGURE 3B. Other services for people with mental health and addictions

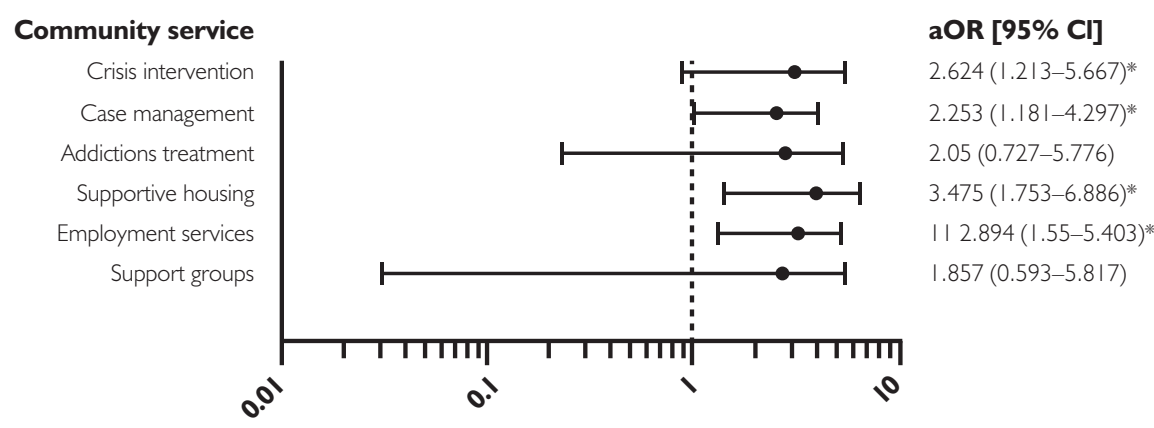

Adjusted Odds Ratio

$*_{p}<0.05$

FIGURE 3C. Services to support chronic disease prevention and management

\section{Community service}

Toronto central diabetes referral service (CS) Telehomecare program (CCAC) (CS)

Diabetes education ${ }^{\S}$

Chronic disease $^{\S}$

Weight management" HIV/Hepatitis C education ${ }^{\S}$

Smoking cessation ${ }^{\S}$

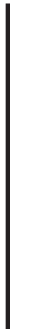

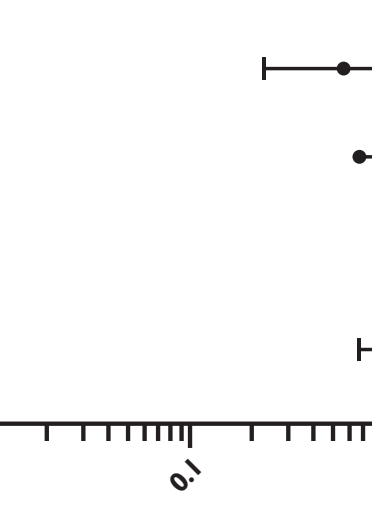

Adjusted Odds Ratio

aOR $(95 \% \mathrm{Cl})$

$0.498(0.268-0.923) *$

$3.408(1.81-6.415) *$

$0.415(0.116-1.486)$

$3.319(1.751-6.293)^{*}$

$2.565(1.318-4.992)^{*}$

1.70। (0.93।-3.1। I)

$2.01(0.92-4.394)$

${ }_{p}<<0.05 . \S N=226 . \uparrow N=225$.

FIGURE 3D. Services to support seniors

\section{Community service}

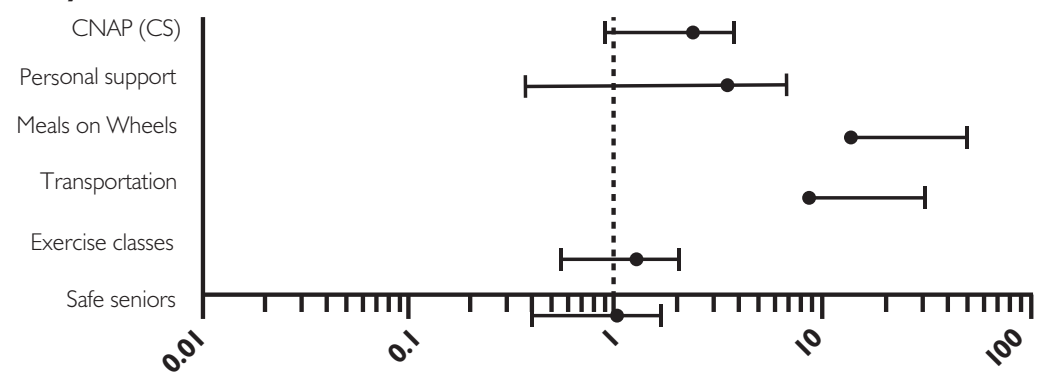

Adjusted Odds Ratio
aOR (95\% Cl)

I.98। ( I.03-3.78। $)^{*}$

$2.532(0.927-6.917)$

$6.94(1.501-32.077) *$

$4.223(0.882-20.218)$

I. 114 (0.614-2.023)

$0.881(0.463-1.677)$ 


\section{Discussion}

We found relatively low awareness among physicians of the Centralized Intake Services available in their region. Most physicians, however, were aware of specific services to support patients with mental health and addictions, chronic disease management and prevention and older adults. In general, awareness of centralized and specific community support services was more than twice as high among physicians practising in a team-based model than among those practising without the support of government-funded health professionals. Teambased physicians reported serving more patients with psychosocial and medical complexity than non-team-based physicians, but also had roster sizes about half as large as non-teambased physicians. Team-based physicians were more likely to be female, younger and with fewer years in practice. Team-based physicians continued to have higher odds of awareness of community services even after adjustment for differences in physician and practice characteristics.

There are several potential explanations for the low awareness of community resources. Services were likely to be ineffectively advertised, and physicians were likely to be unaware of regional websites summarizing available community resources. Physicians need to keep up with rapidly changing medical evidence, and in that context, staying abreast of changes in community services may be challenging and perceived as less important. Centralized Intake Services are meant to streamline and improve access, so low awareness of these is particularly troubling. Auto-integration of community referrals with electronic medical record systems is a promising approach offered by select third-party vendors for specific types of referrals (CognisantMD 2017). Awareness of the centralized diabetes referral was higher among non-team-based practices, and its relative success may offer potential insights for other community programs. More research is also needed to understand whether awareness of specific community resources relates to the perceived usefulness or efficacy of the resource among physicians.

Our findings suggest that patients who attend a team-based primary care model in Ontario may be doubly advantaged. Not only do they have easy access to social workers, dietitians, pharmacists and other health professionals free at the point of care, their physicians are more likely to be aware of existing community resources, including programs to support mental health and for chronic disease management. It may be that team-based physicians learn about community resources from their non-physician colleagues, for example, learning from social workers about available community mental health programs. They may also be more attuned to the benefits of interprofessional care.

Approximately three quarters of Ontarians are not part of a team-based primary care model, and these patients are more likely to be new immigrants, live in lower income neighbourhoods, and live in urban areas (Kiran et al. 2016). More needs to be done to improve their access to non-physician supports and their use of community resources. New Ontario Health Teams are meant to integrate care between primary care and other sectors including community mental health and addiction services (Ontario Ministry of Health and 
Long-Term Care 2019). However, our study warns that these initiatives can potentially worsen inequities in access. For example, there is a risk that early adopters will largely include physicians practising in existing team-based models, providing more streamlined access to community resources for patients who already have better access to non-physician-based health professionals and physicians with more knowledge of community services.

Few other studies have assessed primary care physician awareness of community resources. A study done in another urban area in Canada many years ago also found low awareness of services (Craven et al. 1990). A recent qualitative study found that physicians in team-based models often relied on other team members to stay up-to-date on available community resources for seniors. Participants in that study recommended a central online database with current information on services and resources to enable patient self-referral (Ploeg et al. 2017). A study in British Columbia found that adding a nurse practitioner to a rural primary care practice improved community linkages (Roots and MacDonald 2014). Other recent studies suggest that community health workers may help patients successfully navigate community resources, acting as a bridge between the health system and the broader community (Cosgrove et al. 2014; Najafizada et al. 2015). High-performing practices in the US often have dedicated staff whose sole responsibility is care coordination (Bodenheimer et al. 2014). Qualitative findings from a recent initiative in our region emphasize the importance of providing support in a trusting, collaborative manner to counter feelings of isolation and burnout among community physicians (Lockhart et al. 2019).

\section{Limitations}

There are several limitations worth noting. First, similar to all surveys, ours is open to response bias. Specifically, most respondents in our survey reported working in a team-based model, yet, in the health region, most physicians do not work in a team setting. It is also plausible that physicians who responded to our survey were generally more engaged in the topic area or with the health region. However, these response biases likely underestimate the difference in awareness of community resources between team-based and non-team-based physicians, as we hypothesize that non-responders were disproportionately non-team-based physicians and that these physicians were likely more removed from communications from the regional health authority and less aware of community services. Further, our response rate was close to $40 \%$, which is much higher than that of typical physician surveys (Canadian Medical Association 2018; National Physician Survey 2014). Second, it is possible that our survey underestimated awareness, overall. Respondents may have incorrectly written that they were not aware of a service because they were not familiar with the formal name of the service used in the survey - the survey did not offer a detailed definition for the services included. Third, potential confounders may have influenced our comparison of team-based and non-team-based physicians. Most FHTs in the surveyed region are affiliated with the university and act as training sites for family medicine residents. It is possible that some of the differences we found between team-based and non-team-based physicians relate to the 
presence of family medicine residents. However, the equity implications for patients in the team-based and non-team-based practices remain. In addition, variables such as panel size were self-reported and may not have been entirely accurate. Fourth, we decided a priori not to adjust for multiple comparisons. Doing so would have changed the threshold for statistical significance, but it would not have altered our overall conclusions related to low awareness, especially among non-team-based physicians. Finally, the study occurred in a large, urban area with a diverse population and a large number of community resources. Our findings of low awareness may not be generalizable to health regions encompassing smaller towns or rural communities.

\section{Conclusion}

In summary, we found low awareness of Centralized Intake Services for community resources among primary care physicians practising in an urban area. Physicians practising in team-based models were twice as likely to report awareness compared to those not in a team-based model. Our findings suggest that shared community supports are not a substitute for non-physician health professionals integrated into a team. The latter may play an important role in helping educate physicians and patients about available services. Future research should explore why primary care physicians do not know about services, particularly Centralized Intake Services designed to improve access, and what strategies may increase awareness and use. At the same time, healthcare administrators should consider direct advertising to patients of available community resources. Efforts to improve access to community services and non-physician health professionals should take an equity lens, deliberately targeting underserved groups, to avoid worsening inequities.

\section{Funding Statement}

This study was supported by funding from the Toronto Central Local Health Integration Network. At the time of the study, Dr. O'Campo was the Chair on Intersectoral Solutions to Urban Health Problems. Dr. Kiran is the Fidani Chair of Improvement and Innovation at the University of Toronto. She is supported as a clinician scientist by the Department of Family and Community Medicine at St. Michael's Hospital and at the University of Toronto. She is also supported as an embedded clinician researcher by the Canadian Institutes of Health Research and Health Quality Ontario. The views expressed herein solely represent the authors.

\section{Conflict of Interest}

Tara Kiran was a primary care advisor with the Toronto Central Local Health Integration Network from 2015 to 2016. She has received grant funding from Gilead Sciences Canada.

\section{Acknowledgements}

The authors thank Suzanne Zerger for her contributions to this study. 
Correspondence may be directed to: Tara Kiran, 80 Bond Street, Toronto, ON M5B 1W8. She can be reached by phone at 416-864-3011 or by e-mail at tara.kiran@utoronto.ca.

\section{References}

Barnett, K., S.W. Mercer, M. Norbury, G. Watt, S. Wyke and B. Guthrie. 2012. Epidemiology of Multimorbidity and Implications for Health Care, Research, and Medical Education: A Cross-Sectional Study. The Lancet 380(9836): 37-43. doi:10.1016/S0140-6736(12)60240-2.

Bodenheimer, T., E.H. Wagner and K. Grumbach. 2002. Improving Primary Care for Patients with Chronic Illness. JAMA 288(14): 1775-79. doi:10.1001/jama.288.14.1775.

Bodenheimer T., A. Ghorob, R. Willard-Grace and K. Grumbach. 2014. The 10 Building Blocks of HighPerforming Primary Care. Annals of Family Medicine 12(2): 166-71. doi:10.1370/afm.1616.

Brien, S., L. Grenier, M. Kapral, P. Kurdyak and S. Vigod. 2015. Taking Stock: A Report on the Quality of Mental Health and Addictions Services in Ontario. An HQO/ICES Report. Retrieved July 14, 2019. $<$ http://www.hqontario.ca/portals/0/Documents/pr/theme-report-taking-stock-en.pdf $>$.

Canadian Medical Association (CMA). 2018, October. CMA National Physician Health Survey - A National Snapshot. Retrieved July 14, 2019. <https://www.cma.ca/sites/default/files/2018-11/nph-survey-e.pdf>.

CognisantMD. 2017. Ocean eReferral Network. Retrieved July 14, 2019. <https://www.cognisantmd.com/ ocean-ereferrals/>.

Cosgrove, S., M. Moore-Monroy, C. Jenkins, S.R. Castillo, C. Williams, E. Parris et al. 2014. Community Health Workers as an Integral Strategy in the REACH U.S. Program to Eliminate Health Inequities. Health Promotion Practice 15(6): 795-802. doi:10.1177/1524839914541442.

Craven, M.A., N. Kates and P. Raso. 1990. Assessment of Family Physicians' Knowledge of Social and Community Services. Canadian Family Physician 36: 443-47. doi:10.15212/FMCH.2017.0136.

Glazier, R.H., P. Gozdyra, M. Kim, L. Bai, A. Kopp, S.E. Schultz and A.M. Tynan. 2018, August. Geographic Variation in Primary Care Need, Service Use and Providers in Ontario, 2015/16 [report]. Retrieved July 14, 2019. $<$ https:/www.ices.on.ca/Publications/Atlases-and-Reports/2018/Geographic-Variation-in-Primary-Care>.

Green, M.E., P. Gozdyra, E. Frymire and R.H. Glazier. 2017. Geographic Variation in the Supply and Distribution of Comprehensive Primary Care Physicians in Ontario, 2014/15. Retrieved July 14, 2019. $<$ https://www.ices.on.ca/Publications/Atlases-and-Reports/2017/Geographic-variation-in-physician-supply>.

Hutchison, B., J.F. Levesque, E. Strumpf and N. Coyle. 2011. Primary Health Care in Canada: Systems in Motion. The Milbank Quarterly 89(2): 256-88. doi:10.1111/j.1468-0009.2011.00628.x.

Jaakkimainen, L., R.E. Upshur, J.E. Klein-Geltink, S. Maaten, S.E. Schultz, A. Leong et al. 2006. Primary Care in Ontario: ICES Atlas [report]. Retrieved July 14, 2019. <https://www.ices.on.ca/Publications/ Atlases-and-Reports/2006/Primary-care-in-Ontario>.

Kiran, T., R.H. Glazier, M.A. Campitelli, A. Calzavara and T.A. Stukel. 2016. Relation between Primary Care Physician Supply and Diabetes Care and Outcomes: A Cross-Sectional Study. CMAJ Open 4(1): E8087. doi:10.9778/cmajo.20150065.

Kurdyak, P., A. Butler, C. Adair, W. Jones, S. Vigod, M. Smith et al. 2017, July. Towards Quality Mental Health Services in Canada: A Comparison of Performance Indicators across 5 Provinces. Centre for Applied Research in Mental Health \& Addiction (CARMHA). Retrieved July 14, 2019. <https:/www.sfu.ca/content/dam/sfu/ carmha/resources/2017-toward-quality-mh/CARMHA REPORT_29 Aug_Final.pdf $>$.

Lockhart, E., G.A. Hawker, N.M. Ivers, T. O’Brien, G. Mukerji, P. Pariser et al. 2019. Engaging Primary Care Physicians in Care Coordination for Patients with Complex Medical Conditions. Canadian Family Physician 65(4): e155-62.

Martin, D., A.P. Miller, A. Quesnel-Vallée, N.R. Caron, B. Vissandjée and G.P. Marchildon. 2018. Canada's Universal Health-Care System: Achieving Its Potential. The Lancet 391(10131): 1718-35. doi:10.1016/ S0140-6736(18)30181-8. 
Mental Health Commission of Canada. 2013. Making the Case for Investing in Mental Health in Canada: 1 in 5 People in Canada Lives with a Mental Illness Each Year. Retrieved July 14, 2019. <https://www. mentalhealthcommission.ca/sites/default/files/2016-06/Investing_in_Mental_Health_FINAL_Version_ ENG.pdf $>$.

MHASEF Research Team. 2017. The Mental Health of Children and Youth in Ontario: 2017 Scorecard. Retrieved July 14, 2019. <https://www.ices.on.ca/Publications/Atlases-and-Reports/2017/MHASEF>.

National Physician Survey. 2014. 2014 National Response Rates. Retrieved July 14, 2019.

$<$ nationalphysiciansurvey.ca/surveys/2014-survey/response-rates/>.

Ontario Ministry of Health and Long-Term Care. 2019. Become an Ontario Health Team. Retrieved July 14, 2019. <http://health.gov.on.ca/en/pro/programs/connectedcare/oht/default.aspx>.

Najafizada, S.A.M., I.L. Bourgeault, R. Labonte, C. Packer and S. Torres. 2015. Community Health Workers in Canada and Other High-Income Countries: A Scoping Review and Research Gaps. Canadian Journal of Public Health 106(3): e157-64. doi:10.17269/CJPH.106.4747.

Peckham, A., J. Ho and G.P. Marchildon. 2018, March. Policy Innovations in Primary Care Across Canada: A Rapid Review Prepared for the Canadian Foundation for Healthcare Improvement. North American Observatory on Health Systems and Policies. Retrieved July 14, 2019. <https://ihpme.utoronto.ca/wp-content/ uploads/2018/04/NAO-Rapid-Review-1_EN.pdf>.

Ploeg, J., M. Denton, B. Hutchison, C. McAiney, A. Moore, K. Brazil et al. 2017. Primary Care Physicians' Perspectives on Facilitating Older Patients' Access to Community Support Services: Qualitative Case Study. Canadian Family Physician 63(1): e31-e42.

Reiss-Brennan, B., K.D. Brunisholz, C. Dredge, P. Briot, K. Grazier, A. Wilcox et al. 2016. Association of Integrated Team-Based Care with Health Care Quality, Utilization, and Cost. JAMA. 316(8): 82634. doi:10.1001/jama.2016.11232.

Roots, A. and M. MacDonald. 2014. Outcomes Associated with Nurse Practitioners in Collaborative Practice with General Practitioners in Rural Settings in Canada: A Mixed Methods Study. Human Resources for Health 12(1): 69. doi:10.1186/1478-4491-12-69.

Starfield, B. 1992. Primary Care: Concept, Evaluation, and Policy. Oxford University Press.

Starfield, B., K.W. Lemke, T. Bernhardt, S.S Foldes, C.B. Forrest and J.P. Weiner. 2003. Comorbidity: Implications for the Importance of Primary Care in "Case" Management. Annals of Family Medicine 1(1): 8-14. doi:10.1370/afm.1.

Starfield, B., L. Shi and J. Macinko. 2005. Contribution of Primary Care to Health Systems and Health. The Milbank Quarterly 83(3): 457-502. doi:10.1111/j.1468-0009.2005.00409.x.

\section{Better Healthcare}

... everywhere

Longwoods.com 